\title{
The bachelor-master structure (two-cycle curriculum) according to the Bologna agreement: a Dutch experience
}

J.B.M. Kuks

\section{Summary}

The Groningen Medical Curriculum is an example of a two-cycle curriculum with a course leading to the Bachelor's degree followed by a course at the end of which students receive a Master's degree in medicine. Moreover a third cycle is in the offing, in the form of a PhD trajectory for students who wish to pursue a career in research. The Groningen curriculum is based on the CanMEDS competency model. In addition to describing the Groningen curriculum, the author comments on the opportunities and threats offered by the bachelor-master structure. A plea is made for more vigorous collaboration in working towards a more uniform European medical curriculum with room for specific local features at the discretion of individual universities. (Kuks JBM. The bachelor-master structure (two-cycle curriculum) according to the Bologna agreement: a Dutch experience. Netherlands Journal of Medical Education 2010;29(1):16-21)

\section{The fist medical master in Europe}

The Bologna medical master is a reality: On September 17th, 2009 the first official graduation ceremony of Medical Masters in Europe took place at the University Medical Centre of Groningen (UMCG). This festive event is a landmark in the implementation of the bachelor-master process that was initiated with the signing of the Bologna declaration. The bachelormaster structure has been embraced by all eight medical faculties in the Netherlands, ${ }^{1}$ and in 2003, Groningen University was the first to introduce a two-cycle medical curriculum: 'G2010'.

Does the graduation ceremony of the Groningen medical masters really mark a milestone on the road to implementation of the Bologna process or would it be a more appropriate comment to repeat after Shakespeare: 'What's in a name?'

\section{The Bologna process: strengths,} weaknesses, opportunities, threats

The strength of the Bologna reforms is that they concentrate on 1) a three-cycle degree structure (bachelor - master - doctorate), 2) quality assurance and 3) recognition of qualifications and periods of study. As a consequence, the European higher education area can become a reality, enhancing student mobility and creating a transparent degree structure based on a uniform credit system. ${ }^{2}$

It seems self evident that these concepts deserve a warm welcome, and at first sight there are no a priori weaknesses. However, potential threats and difficulties have been identified and concerns regarding the Bologna reforms of medical education have been voiced. Nowadays many medical schools have a curriculum that is characterized by clinical medicine as a clearly identifiable thread, running through the curriculum from start to finish. Although basic science does have a prominent place, it is taught within the context of clinical problems. ${ }^{3}$ Thus the old system with basic science in the first cycle and clinical medicine in the second cycle has been effectively abandoned, but the advent of the bachelor-master system 
could be perceived as heralding the return of the olden days of separate preclinical and clinical curricular phases. A second threat is undesirable uniformization. For, if the many differences between European medical schools are all levelled out, schools will be at risk of losing the very features that make them stand out among the other universities. In other words, schools stand to lose their unique identities and defining characteristics. Thirdly, there is the problem of multilingualism as a barrier to mobility of medical students within Europe. Because it is considered crucial for medical education to be patient centred, most components of medical programmes require communication with patients, and patients want to present their complaints and concerns in their own language or even their own regional dialect. Thus mobility is up against a language barrier. And finally: will it actually be feasible to set uniform objectives for medical education in the whole of Europe? For example: in the Netherlands, recent medical graduates have very limited experience with obstetrics and much of the learning in that area is deferred until postgraduate training. Would this be acceptable in other countries as well?

And last but not least, Bologna offers opportunities. The Bologna reforms imply uniform quality assurance, transparency of degrees and uniform objectives for medical education, the high priority of which is strongly stressed by student delegations. Furthermore, in addition to flexibility of movement of medical students within Europe, mobility of students between medical and other programmes might be enhanced by widespread adoption of a uniform bachelormaster structure. Students not wanting to continue their medical studies after achieving their Bachelor's degree would be able to switch to a master programme in a different subject, and students with a Bachelor's degree in a subject related to medicine could enter the medical master programme, either directly or after completing a transitional programme.

\section{The Groningen G2010 competency based curiculum}

To meet the Bologna objectives the Groningen curriculum planning group designed a two-cycle curriculum, consisting of a three-year bachelor programme and a three-year master programme, each being the equivalent of 180 European Credit Transfer and accumulation System (ECTS) credits, or 60 credits per year.

A special effort was made to bring the curriculum in line with the competencies of the Canadian Medical Education Directives for Specialists (CanMEDS), which were making their entrance on the medical education stage at the time G2010 was being developed. In order to make this possible, the CanMEDS competencies (see Table 1), which are described as physician roles and were originally designed for postgraduate training, were adapted for undergraduate medical education. This resulted in a rosette of seven competencies with three domains each, arranged around a centre of required medical knowledge as presented in the table. The three domains were defined in such a way that the first level could be fully covered during the bachelor period.

The G2010 programme is patient oriented from the very beginning. Each week of the bachelor programme starts with a session in which a patient is present who has a clinical problem that is related to that week's topic. For example, a patient with muscular dystrophy is present in a session introducing a topic featuring the anatomy, histology and physiology of the musculoskeletal system. 
There is a great deal of attention paid to basic sciences but other competencies are addressed too, such as communicating with patients with a chronic disease, choices concerning diagnostic work up, recent developments in neuromuscular sciences, clinical examination, therapeutic (im)possibilities, public health issues concerning patients with severe disabilities and reflection on the autonomy of dependent patients.

\section{A spiral curriculum structure}

The G2010 curriculum has a spiral structure $^{4}$ and addresses the vectors attitude, cognition and skills. Topics are revisited at increasing levels of difficulty as students' competencies increase. Basic sciences and their links to clinical problems are stressed in the first bachelor year; clinical topics with links to basic science topics are stressed in the second and third bachelor years; dual learning in a skillslab setting, in parallel with clerkships, is the focus of the first master year; regular clerkships constitute the programme of the second master year; and a 20-week clinical elective and a 20 -week research elective form the programme of the third master year.

Not only do students attend lectures they also take part in practical workshops and in tutorials in which 10 students work, guided by a teacher. This small group format starts in the first year and continues until the last year. It is aimed at development of different competencies, such as the use of scientific research

Table 1. CanMEDS competencies.

\begin{tabular}{|c|c|c|}
\hline \multicolumn{2}{|c|}{ Competencies } & Domains \\
\hline 1 & Communicative skills & $\begin{array}{ll}1 & \text { Communication with other students } \\
2 & \text { Communication with patients } \\
3 & \text { Communication with medical colleagues }\end{array}$ \\
\hline 2 & Clinical problem solving & $\begin{array}{ll}1 & \text { Problem description } \\
2 & \text { Rational diagnostics } \\
3 & \text { Functional and effective treatment }\end{array}$ \\
\hline 3 & Using knowledge and science & $\begin{array}{ll}1 & \text { Methods and techniques } \\
2 & \text { Scientific foundation of medicine } \\
3 & \text { Science and society }\end{array}$ \\
\hline 4 & Patient investigation & $\begin{array}{ll}1 & \text { History taking } \\
2 & \text { Clinical examination and investigations } \\
3 & \text { Treatment strategies }\end{array}$ \\
\hline 5 & Management strategies & $\begin{array}{ll}1 & \text { Aims and possibilities of treatment } \\
2 & \text { Making a choice and a start } \\
3 & \text { Continuity and adjustment }\end{array}$ \\
\hline 6 & $\begin{array}{l}\text { Social and community } \\
\text { context of health care }\end{array}$ & $\begin{array}{ll}1 & \text { Non-biological factors in health and disease } \\
2 & \text { Screening and prevention } \\
3 & \text { Health care organization, law, history }\end{array}$ \\
\hline 7 & Reflection & $\begin{array}{ll}1 & \text { Self and professional } \\
2 & \text { Ethics and moral decision making } \\
3 & \text { Medical philosophy }\end{array}$ \\
\hline
\end{tabular}


methods, clinical problem solving according to Barrow's ${ }^{5}$ notions of problem-based learning and reflection on working in health care. It thus supports coherence of the spiral structure described above.

\section{Knowledge and knowledge management}

In the bachelor programme students are introduced to basic science concepts that are used during the master programme and thereafter. One of the aims of medical education today is to prepare students to be lifelong learners. This is essential in a rapidly expanding scientific field such as medicine. Modern students are no longer forced to digest the complete contents of textbooks, which will be largely outdated before long and are increasing in size constantly. In a context of rapidly changing and expanding knowledge it is not sufficient for students to acquire factual knowledge, they also have to learn how to manage knowledge. Consequently, skills for lifelong learning should be given high priority in medical education. In G2010, a distinction is made between core knowledge (which students must master and be able to use without recourse to reference materials) and back-up knowledge (to be acquired by studying set texts and readings but not requiring rote learning). A small part of all written exams consists of questions that must be answered without using references (closed book section) and the rest of the exams consists of open book questions related to subjects addressed during lectures, practical workshops and other educational activities.

\section{Graduate entry programme}

The G2010 curriculum was developed for cohorts of 440 students. Students with a Bachelor's degree in subjects related to medicine, such as pharmacy, psychology and movement sciences, can enter the master programme after completing a one-year graduate entry programme. Every year some 160 students apply for admittance to this programme. After an admission test, approximately 40 students start the programme and nearly all of them finish it successfully after one year. The graduate entry programme combines the second and third bachelor years and students are encouraged to study basic sciences too, depending on their knowledge defects in that area.

\section{The third cycle}

During the first years of the Bologna process the aim was to develop a two-cycle bachelor-master programme, but in the course of time a third cycle was added: the PhD cycle. Not all medical students want to earn a PhD degree, but students who show a marked interest in scientific research can be spotted at an early stage. G2010 contains a bachelor honours programme for research training which is equivalent to 30 ECTS credits. After completing the honours course, students can apply for a place as a PhD student and take part in an extended programme, leading to a PhD degree and a Master's degree in medicine. About $10 \%$ of the students undertake this Master's/PhD degree track. For most of them this takes five years to complete as opposed to three years for the regular Master's degree programme only.

\section{Quality assurance system}

In order to achieve and maintain a highquality programme, a continuous quality assurance process is in place. After each module, student representatives produce an extensive evaluation report in which they comment on the programme, the lectures, other educational activities, the quality of readers and assignments, the validity of the exams and any other topic they consider relevant. The whole student 
population is surveyed and the teachers are interviewed. The results of this process are written up in a report, which is discussed at several levels of the medical school. Student representatives and core teachers prepare improvements to deal with the comments, and these are implemented when the module is next offered. Medical schools have to take part in a mandatory national external quality assurance round every six years in order to ensure re-accreditation of the curriculum.

\section{From the bachelor-master pro- gramme to medical practitioner}

The UMCG Bachelor's degree guarantees entry to the master programme. More than $90 \%$ of students obtain their Bachelor's degree and nearly all of them continue with the master programme without interruption. So the annual cohorts of (about 400) master students consist of students who have completed the UMCG bachelor programme and students who have completed the one-year graduate entry programme $(10 \%)$. In the Netherlands, a Bachelor's degree does not grant a vocational qualification and students have to complete the medical master programme or another programme if they wish to be able to use what they have learned in their work as a professional.

The Master's degree in medicine means that students are licensed to practise medicine independently as a medical doctor.

\section{So now the job has been done?}

In the foregoing I described the concept and the details of our G2010 curriculum, which meets the objectives as described in the Bologna process. Did we really create a new curriculum or was it simply a matter of sticking new labels on old items? We divided the G2010 curriculum into a bachelor and a master programme, and this meant we had to (re)define our learning objectives and levels of mastery, so we think that much of our bachelor and master programmes is quite new. As a consequence, students with a Bachelor's degree in a different subject are allowed to enter our master programme (including, by implication, students with a Bachelor's degree from another medical school), students can enter the third, PhD, cycle, ECTS credits are used, a quality assurance system is in place and there is strong involvement of students in curricular development. Finally, we have just graduated our first master students. One might be tempted to think that everything is perfect and nothing is left to be desired. That, however, would seem to be a far cry from today's reality.

Due to logistical reasons we are unable to admit more than a few students from other universities to our master programme, because most of our students stay on at UMCG to continue their master programme immediately or at most they are absent only temporarily to do an elective elsewhere.

Furthermore we used our own judgement in determining the learning outcomes for the bachelor programme. For even though medical education in the Netherlands has to meet the objectives set out in the revised Framework 2009, ${ }^{3}$ the committee revising the Framework has not indicated how basic science knowledge is to be distributed over the bachelor and the master programmes.

In G2010, clinical skills training does not start until the first year of the master programme in order to make the medical master programme more accessible for students with non-medical Bachelor's degrees. Furthermore we feel that it is more effective to teach the skills for clinical encounters with patients at the very moment when students actually have to use them in the clinical setting, ${ }^{7}$ and this is not before the master period. Other Dutch 
medical schools offer clinical skills training, and some schools even offer clerkships, much earlier in the curriculum. These differences thwart the uniformity of programmes required to successfully implement the Bologna ideas, and more congruence will be needed in this respect. The Dutch Framework 2009 merely states that in order to obtain the Bachelor's degree students must be able to examine a patient, but fails to specify any details of this requirement.

So, even if we wish to implement the Bologna process in a region as small as the Netherlands, a great deal of work will have to be done to create consensus on the medical curriculum among medical schools. On a Europe-wide scale, matters are only more complicated - with so far less than $30 \%$ of the participating countries having made a commitment to implement the Bologna process in medical education - let alone that consensus on content, sequencing and length of curricular components seems within reach. Finally, language issues will have to be dealt with to facilitate mobility of medical students, for clinical electives in particular.

In spite of these obstacles, I believe we should not continue to develop medical curricula at regional or national levels without looking across borders and taking notice of the numerous opportunities that can be offered by a Europe-wide Bologna process - if only we would link hands and turn our words into deeds. The next step will not be to try to adopt (parts of) each other's programmes but rather to discuss how we can face threats and resolve problems, and then collectively work towards consensus about minimum requirements for a uniform bachelor-master curriculum to be offered by all universities that are willing to put this system to the test. Thereafter the other medical schools will be able to see what is possible and hopefully will be persuaded to join the Bologna process.

After this has been achieved, intra-European mobility between medical schools will be greatly enhanced and European medical degrees will gain increasing recognition and legal acceptance in the participating countries. Moreover, European medical schools with well-defined outcomes and diplomas will be more attractive to non-European immigrant students as well.

\section{References}

1. Patricio M, den Engelsen C, Tseng D, ten Cate O. Implementation of the Bologna two-cycle system in medical education: where do we stand in 2007? Med Teach 2008;30(6):597-605.

2. The Bologna Process - Towards the European Higher Education Area. http://ec.europa.eu/ education/higher-education/doc1290_en.htm

3. Dutch Blueprint: Raamplan Artsenopleiding 2009. Nederlandse Federatie van Universitaire Medische Centra. [The 2009 Framework for Undergraduate Medical Education in the Netherlands. Utrecht: Dutch Federation of University Medical Centres, 2009].

4. Harden RM, Stamper N. What is a spiral curriculum? Med Teach1999;21(2):141-143.

5. Barrows HS. Problem based self directed learning. JAMA 1983;250(22):3077-3080.

6. Cohen-Schotanus J, Schönrock-Adema J, Bouwkamp-Timmer T, van Scheltinga GR, Kuks JBM: One-year transitional programme increases knowledge to level sufficient for entry into the fourth year of the medical curriculum. Med Teach 2008,30(1):62-6.

7. Van Hell EA, Kuks JBM, Schönrock-Adema J, Van Lohuizen MT, Cohen-Schotanus J. Transition to clinical training: influence of pre-clinical knowledge and skills, and consequences for clinical performance. Med Educ 2008;42: 830-837.

The author

J.B.M. Kuks, MD PhD, is professor neurology and medical education, former director of the Medical Curriculum, University Medical Centre Groningen (UMCG), the Netherlands.

Correspondence

Prof. dr. J.B.M. Kuks, neurologist, University Medical Centre Groningen, the Netherlands.

E-mail:j.b.m.kuks@med.umcg.nl

No potential conflict of interest relevant to this article was reported 